\title{
Psychomotor slowing and subcortical-type dysfunction in depression
}

\author{
ROBERT P HART, JOSEPH A KWENTUS \\ From the Departments of Psychiatry, Neurology and Surgery, Medical College of Virginia, Virginia \\ Commonwealth University, Richmond, VA, USA
}

SUMMARY Elderly patients with major depression and normal controls completed the Sternberg short-term memory scanning procedure and WAIS Digit Symbol. Depresssed patients demonstrated psychomotor slowing on both tasks, but normal response latency as a function of memory set size on the Sternberg procedure. While cognitive-behavioural slowing may be observed in both depressive illness and subcortical neurological disorders, a normal rate of processing information centrally appears to distinguish depression from certain of these disorders. Psychomotor slowing in the presence of normal information processing speed might be explained by a deficit in motivational state associated with depression.

The cognitive deficits often observed in patients with depression or depressive pseudomentia resemble those attributed to "subcortical dementia". 12 The term subcortical dementia refers to behavioural changes associated with disorders in which primary neuropathology is located in subcortical brain. regions. ${ }^{13-5}$ Although this term lacks specific neuroanatomical reference and may falsely imply the absence of cortical dysfunction, ${ }^{6}$ it is used to describe a constellation of behavioural changes which seem characteristic of patients having subcortical pathology. These changes include cognitive slowing, forgetfulness or deficient retrieval, intellectual "dilapidation" and alterations in personality and affect such as apathy, decreased drive and depression. ${ }^{147}$

Benson ${ }^{1}$ points out that psychomotor retardation, a "common behavioural sign in major depression", is the most characteristic feature of subcortical dementia. Caine ${ }^{2}$ also suggests that the inattention, slowed mental processing, decreased spontaneous verbal elaboration and deficient analysis of detail frequently seen in depressed patients represent a "subcortical" pattern of cognitive impairment. Perhaps the most characteristic clinical feature shared by depression and certain subcortical neurological disorders is

Address for reprint requests: Robert P Hart, Ph.D., Box 268, Medical College of Virginia, Richmond, VA 23298, USA.

Received 9 September 1986 and in revised form 28 January 1987. Accepted 30 January 1987 cognitive and/or psychomotor slowing. One paradigm useful for measuring these functions is the memory scanning procedure developed by Sternberg. ${ }^{8}$ In this task, speed and accuracy of short-term memory retrieval are measured independently and motor demands remain constant while the amount of information to be processed varies. Slowed memory scanning speed on the Sternberg task has been demonstrated in neurological disorders such as Parkinson's disease ${ }^{9}$ and Friedreich's ataxia ${ }^{1011}$ in which the location of primary neuropathology is subcortical nuclei or white matter tracts. If major depressive illness produces a pattern of cognitive impairment which resembles subcortical dementia, then memory scanning speed may be slowed. We examined this hypothesis by administering the Sternberg memory scanning task to elderly patients with major depression and normal controls matched for age and education.

\section{Method}

\section{Subjects}

The subjects consisted of 15 depressed patients (mean age $=$ 70.4 years $\pm 5 \cdot 2$; mean education $=13.8 \pm 3.3)$ and 16 normal controls (mean age $=69.7$ years \pm 4.9 ; mean education $=13.9 \pm 3.5$ ). Depressed patients met DSM-III criteria ${ }^{12}$ for Major Affective Disorder. Most were initially referred for neuropsychological evaluation because of behavioural changes which raised a question of dementia, and all complained of cognitive impairment. Cognitivebehavioural changes included diminished ability to think, concentrate or memorise and were consistent with DSM-III 
criteria for a major depressive episode. Medical history, neurological examination and laboratory studies were used to rule out neurologic disorders and major medical illness. We were careful to exclude depressed patients with subtle signs of extrapyramidal or cerebellar dysfunction since these patients may be at high risk for developing a dementia. ${ }^{13}$ Two such patients presenting with major depression were diagnosed at follow up with multi-system atrophy and excluded from our final sample. All depressed patients completed the Diagnostic Interview Schedule, ${ }^{14}$ a psychiatric interview, and neuropsychological evaluation to establish diagnosis. In all cases the psychiatrist and neuropsychologist agreed on clinical diagnosis. The mean Hamilton Depression rating ${ }^{15}$ at the time of the study was $33 \cdot 1 \pm 10 \cdot 0$. Patients were tested prior to antidepressant treatment. Normal controls were healthy volunteers from the community, screened on the basis of neurological examination, psychiatric interview, and medical history. Informed consent was obtained prior to testing.

\section{Procedure}

After completing diagnostic procedures, all subjects were administered the Digit Symbol subtest from the WAIS and the short-term memory scanning procedure. Clinical diagnoses were made without knowledge of these test results. Digit Symbol was included as a measure of psychomotor speed, and for our purposes subjects were instructed to complete every item on the answer sheet before stopping.

In the short-term memory scanning procedure, subjects faced a monitor interfaced with an Apple Ile computer and placed one thumb on a "yes" button and the other on a "no" button. A session consisted of 192 trials broken into 12 blocks of 16 trials each. Prior to each trial block, the subject was shown on the monitor 1,2 , or 4 digits to remember. Within each trial block, a single digit appeared on the monitor and the subject was instructed to decide whether or not this probe digit belonged to the set of to-be-remembered digits and to press the appropriate button as quickly as possible. The sequence of events on a given trial was as follows: (1) display of warning stimulus for 1.0 second, (2) display of probe digit until response is made, and (3) an inter-trial interval of 2.0 seconds. The probability of the probe digit belonging to the set of to-be-remembered digits was held constant at 0.5 across the three memory set sizes. The order of set size was randomised for the first three blocks, and this sequence was repeated throughout the session. Subjects were first given a practice session consisting of one block of four trials at each memory set size. Brief rest periods between consecutive blocks of trials minimised fatigue. Response category and reaction time were obtained for each trial. The zero intercept of reaction time-set function is taken as a sum required for the motor response and other unknown processes whose duration are unrelated to memory set size. The slope of this function is taken as time needed to scan one item in short-term memory.

\section{Results}

Total time to complete digit-symbol items, and the intercept, slope and error score from the short-term memory scanning procedure are presented in the table. Multivariate analysis of variance of these four
Table Test performance

\begin{tabular}{lcclrr}
\hline & \multicolumn{3}{c}{ Depressed $n=15$} & & \multicolumn{2}{c}{ Controls $n=16$} \\
\cline { 2 - 3 } \cline { 6 - 7 } Measure & $M$ & $S E$ & & $M$ & $S E$ \\
\hline Digit symbol (seconds) & $306.4^{*}$ & 29.5 & & 184.2 & 9.0 \\
Memory scanning: & & & & & \\
Intercept & $870.0 \dagger$ & 99.2 & & 685.0 & 23.5 \\
Slope & 61.4 & 11.5 & & 56.6 & 6.5 \\
Errors & 6.3 & 1.6 & & 3.9 & 1.1 \\
\hline
\end{tabular}

${ }^{*} \mathrm{p}<0.001$ compared with controls, $\mathrm{F}(1,29)$.

tp $<0.07$ compared with controls, $F(1,29)$.

measures revealed an overall effect of Group, $F(4,26)$ $=4.02, \mathrm{p}<0.02$. Follow up tests indicated that depressed subjects took longer to complete digitsymbol items, $F(1,29)=16.56, p<0.001$ and tended to have higher zero intercepts on the memory scanning procedure, $F(1,29)=3.48, p<0.07$. The figure shows that the slope functions were similar for the two groups, but that response latencies of depressed subjects were longer than those of controls at each memory set size. A multivariate approach to repeated measures was used to examine group differences in response latency. In this two-factor design the multivariate analysis for Group effect reduces to a univariate test because the only other factor is the one within subjects factor of memory set size. This

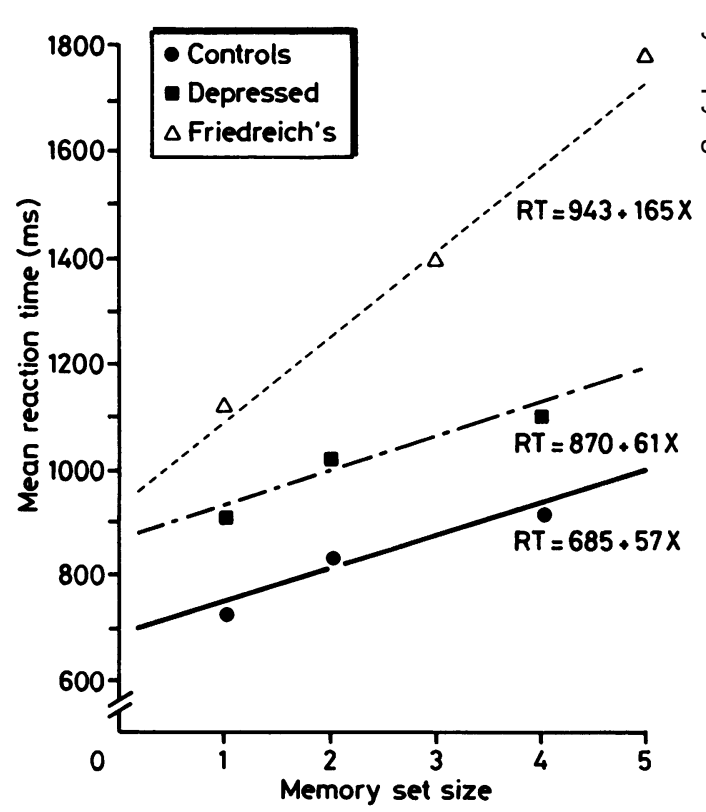

Fig Mean response latencies for depressed $(N=15)$ and normal $(N=16)$ elderly. Data are also presented from a previous study of Friedreich's ataxia patients. ${ }^{10}$ The "yes" and "no" responses are combined for all subjects. 
analysis yielded an effect of Group, $F(1,29)=3.93$, $\mathrm{p}<0.06$, confirming what the figure illustrates.

Response latencies averaged across all three memory set sizes tended to be longer for both groups on negative trials (that is, trials in which the probe digit did not belong to the set of to-be-remembered digits), p's $<0.002$. A multivariate approach to repeated measures revealed that the effect of negative vs positive trials on response latency was exaggerated for depressed patients relative to normal elderly, $F(1,29)=6.91, p<0.02$. Both groups tended to make more errors on negative trials (p's $<0.09$ ), but they did not differ from one another.

The figure also presents for comparison previously reported ${ }^{10}$ memory scanning data from three Friedreich's ataxia patients (mean age $=27.0$ years $\pm 9 \cdot 2$; mean education $=12.0 \pm 0)$. These patients had both higher slopes and larger intercepts than agematched controls. The elevated slope is interpreted as a deficit in information processing speed.

\section{Discussion}

Patients with major depression demonstrated psychomotor slowing in completing digit-symbol items and in responding to probe digits during the short-term memory scanning procedure. However, response latency as a function of memory set size was unimpaired, suggesting a normal rate of information processing. These findings are consistent with the results obtained by Hilbert et $\mathbf{l}^{16}$ who studied memory scanning in younger (mean age $=57.2$ ) mildly depressed (mean Hamilton score $=16.8$ ) patients. Our study extends these findings to a sample of moderate to severely depressed patients presenting with behavioural signs and symptoms initially suggestive of early dementia.

An impairment in arousal-activation mechanisms which modulate higher cortical centres has been postulated as an explanation for cognitive deficits associated with both depressive illness ${ }^{2}$ and subcortical pathology. ${ }^{3}$ Our findings suggest that different psychobiologic mechanisms may in part underlie the cognitive-behavioural slowing observed in depression and certain subcortical neurological disorders. In both Parkinson's disease and Friedreich's ataxia psychomotor-cognitive slowing is a characteristic abnormality. ${ }^{17}$ In contrast to our depressed subjects, however, Wilson et $a l^{9}$ found that nondemented Parkinson's disease patients demonstrate abnormally long response latencies as a function of memory set size on the Sternberg task. ${ }^{9}$ We obtained similar results in our earlier studies of Friedreich's ataxia patients having minimal disruption of higher cortical functions. ${ }^{1011}$ This pattern of performance, also evident following head trauma, suggests slowed infor- mation processing. Interestingly, slowed information processing in Friedreich's ataxia patients appeared to be related to the degree of neurological impairment, but not to levels of depression or other psychological disturbance. Although the neuroanatomical basis of slowed information processing remains unclear, the specific neurochemical changes associated with major depression contrast with the widespread structural changes found in such disorders as Friedreich's ataxia, Parkinson's disease and head trauma.

Our depressed subjects, like nondemented Parkinsonian and Friedreich's ataxia patients, had longer response latencies overall than age-matched controls. Sternberg has postulated that longer latencies and higher zero intercepts represent slowed encoding/perception, decision-making and/or execution of motor responses. The fact that a pattern of longer response latencies on negative trials was exaggerated in the patient group suggests that inefficient decision-making contributes to cognitive-behavioural slowing in depression.

Cognitive impairment in depression has been related to neurochemical or neurophysiological derangements, and characterised as a "dementia syndrome of depression" 18 or reversible organic mental disorder. ${ }^{19}$ Weingartner ${ }^{20}$ has proposed that a general deficit in central motivational state mediated by catecholiminergic systems can explain the impaired performance of depressives on effort-demanding motor and cognitive tasks. ${ }^{21}$ On memory tasks, for example, depressed patients perform better under experimental conditions which do not require effortful encoding or retrieval strategies. ${ }^{223}$ The performance of depressed patients on effort-demanding memory tasks improves following treatment with levodopa or amphetamine. ${ }^{2425}$ The present findings might be explained in a similar manner. A deficit in central motivational state might not affect the rate at which information is transmitted or processed centrally. However, motivational deficiencies would be expected to influence the speed with which decisions are made, information is encoded, and/or motor responses are completed because of the cognitive effort required.

In summary, our results with depressed and Friedreich's ataxia patients in combination with those from an earlier study of Parkinson's disease patients using the same paradigm suggest at least one important difference between depressive illness and subcortical pathology. Although psychomotor slowing may be observed in both depressive illness and subcortical neurologic disorders, a normal rate of central information processing may distinguish depression from the latter disorders. These findings should be replicated, particularly for groups of depressed and Parkinson's disease patients. 
This research was supported by NIMH Grant No. 1 RO1 MH39135-01. The authors thank Marc A Rozner, Ph.D. for his development of computer software for the memory scanning procedure and Robert Hamer, Ph.D. for his assistance in analysing these data.

\section{References}

1 Benson DF. Subcortical dementia: a clinical approach. In: Mayeux R, Rosen WG, eds. The Dementias. New York: Raven Press, 1983:185-94.

2 Caine ED. Pseudodementia. Arch Gen Psychiatry 1981;38:1359-64.

3 Albert ML, Feldman RG, Willis AL. The "subcortical dementia" of progressive supranuclear palsy. $J$ Neurol Neurosurg Psychiatry 1974;37:121-30.

4 Cummings JL, Benson FD. Subcortical dementia: review of an emerging concept. Arch Neurol 1984;41:874-9.

5 McHugh PR, Folstein MF. Psychiatric syndromes of Huntington's chorea: a clinical and phenomenologic study. In: Benson DF, Blumer D, eds. Psychiatric Aspects of Neurologic Disease. New York: Grune \& Stratton, 1975:267-86.

6 Whitehouse PJ. The concept of subcortical and cortical dementia: another look. Ann Neurol 1986;19:1-16.

7 Huber SJ, Paulson GW. The concept of subcortical dementia. Am J Psychiatry 1984;142:1312-7.

8 Sternberg S. Memory Scanning: new findings and current controversies. $Q J$ Exp Psychol 1975;27:1-32.

9 Wilson RS, Kaszniak AW, Klawans HL, Garron DC. High speed memory scanning in Parkinsonism. Cortex 1980;12:67-72.

10 Hart RP, Kwentus JA, Leshner RT, Frazier R. Information processing speed in Friedreich's ataxia. Ann Neurol 1985;17:612-4.

11 Hart RP, Henry GK, Kwentus JA, Leshner RT. Information processing speed in children with Friedreich's ataxia. Devel Med Child Neurol 1986;28:310-3.
12 American Psychiatric Association. Diagnostic and Statistical Manual of Mental Disorders, Third Edition. Washington, D.C. 1980.

13 Reding M, Haycox J, Blass J. Depression in patients referred to a dementia clinic. Arch Neurol 1985;42:894-6.

14 Robins LN, Helzer JE, Croughin J, Ratcliff KS. National Institute of Mental Health Diagnostic Interview Schedule: Its History, Characteristics and Validity. Arch Gen Psychiatry 1981;38:381-9.

15 Hamilton M. Development of a rating scale for primary depression. Br J Soc Clin Psychol 1967;6:278-96.

16 Hilbert NM, Niederehe G, Kahn RL. Accuracy and speed in memory in depressed and organic aged. Educational Gerontology: An International Quarterly 1976;1:131-46.

17 Cummings JL, Benson DF. Dementia: A Clinical Approach. Boston: Butterworth 1983.

18 Folstein MF, McHugh PR. Dementia syndrome of depression. In: Katzman R, Terry RD, Bick KI, eds. Alzheimer's Disease, Senile Dementia and Related Disorders. New York: Raven Press 1978.

19 McAllister TW. Overview: pseudodementia. Am J Psychiatry 1983;140:528-33.

20 Weingartner H. Psychobiological determinants of memory failures. In: Squire L, Butters N, eds. Neuropsychology of Memory. Hillsdale, NJ: LEA Press 1984:203-12.

21 Cohen RM, Weingartner H, Smallbert SA, Pickar D, Murphy DL. Effort and cognition in depression. Arch Gen Psychiatry 1982;39:593-7.

22 Weingartner H, Cohen RM, Murphy DL, Martello J, Geralt C. Cognitive processes in depression. Arch Gen Psychiatry 1981;38:42-7.

23 Miller E, Lewis P. Recognition memory in elderly patients with depression and dementia: A signal detection analysis. $J$ Abnorm Psychol 1977;86:84-6.

24 Henry GW, Weingartner H, Murphy DL. Influence of affective states and psychoactive drugs on verbal learning and memory. Am J Psychiatry 1973;9:966-71.

25 Reus VI, Silberman E, Post RM, Weingartner H. dAmphetamine: effects on memory in depressed population. Biol Psychiatry 1979;14:345-56. 